\title{
Some observations on memory artifice
}

\author{
JOHN ROSS and KERRY ANN LAWRENCE, The University \\ of Western Australia, Nedlands, W. A. 6009
}

Two studies with an ancient memory system demonstrate that capacity in serial learning tasks and paired associate tasks is raised by at least an order of magnitude. It is also shown that serial position effects and proactive inhibition effects are notably absent. Performance of normal Ss using the memory system is compared with a reported case of exceptional memory.

The purpose of the observations reported here was to test the effectiveness of a system of memory artifice which traces to Greece and Rome in their classical periods.

The ancient art of memory, which still persists in debased forms, was practiced seriously by Roman orators (Yates, 1966). Cicero reduced it to two main principles. One was the selection of loci and the other, the construction of imagines. He advised orators to select a sequence of places along a walk. The rooms and distinctive features of a large, quiet building were especially recommended. The places in their proper order constituted the loci. To commit things (res) to memory the orator was taught to form a striking image connecting literal or symbolic representations of each thing with successive loci. Revisiting each place in imagination evoked the image and the image brought the appropriate thing to mind.

The method used in the studies reported is based on Cicero's principles. The observations focus on memory span, interference effects, serial learning, and some stimulus variables such as concreteness vs abstractness.

\section{STUDY 1}

\section{Subject}

The junior author served as S. E was the senior author.

Procedure

The $\mathrm{S}$ was instructed to select and commit to memory 52 loci in sequence along a walk through the grounds of the University of Western Australia. Subsequently E read lists of words with instructions to construct images connecting the words with loci.

Recall was tested after presentation of each whole list under serial order instructions or, where appropriate, under paired associate instructions. Each list was presented once only.

All lists except the last were constructed at the whim of the E. Lists contained common concrete nouns (e.g., bird, matchbox, shoe, motor-car) or abstract nouns (e.g., pattern, condition, jealousy, envy, etc.).

Results

Loci. After two walks $S$ could repeat the loci fluently in forward or backward order.

Lists. In the first session E read a list of 50 concrete nouns, $S$ setting the pace by nodding when ready after each item. Presentation was at the rate of approximately one item every 5 sec. After hearing the complete list $S$ was asked for verbal recall of alternate items in serial order. $S$ made no errors of content or order.

The list was read again in a new order, the items being haphazardly reassigned to new serial positions. When asked for verbal recall of alternate items in the new order $S$ made two errors, both omissions.

$\mathrm{S}$ was asked, without warning, for written recall of the complete list of 50 items in the original order. She made only two errors, both omissions.

Pairs. Two lists, A and B, each containing 20 concrete nouns were used in the second session, one week after the first. $E$ read List $A$, as in the first session, and asked for immediate verbal recall of all 20 items in serial order. E then read 20 pairs, the first item of each from List $A$ and the second from List $\mathrm{B}$, maintaining the original order for List A. Rate of presentation was approximately the same as in the first session. S had four tasks: (1) to recall all $20 \mathrm{~A}-\mathrm{B}$ pairs in serial and A-B order, (2) to recall the paired B members given the A members in a new order, (3) to recall the B member if given the $A$ member, and the $A$ member if given the $B$ member, the pairs being presented in another new order, and, finally, (4) to repeat task (1). All recall was spoken.

The $\mathrm{S}$ made no errors in any of the tasks. Retested four days later on Task (1) without further presentation of material, $S$ made one error of A-B order within the eighth pair.

The procedure of the second session was repeated in the third, which followed 10 days later, using two lists each of 20 abstract nouns.

The S made one error on Task (1), substituting "jealousy" for "envy" but no errors on any of the other tasks, nor on Task (1) both one day and three days later.

After completion of all tasks on the first day of the third session, $\mathrm{S}$ was retested without further presentation on Task (1) from the previous session (concrete nouns) and made no errors.

\section{Subjects}

\section{STUDY 2}

Five senior students in Psychology served as Ss. E was the junior author.

Procedure

All Ss learned a walk of 52 loci (all within two trials) and were subsequently required to memorize a practice test of 40 words presented once only. Three days later experimental sessions began. Ss were required to memorize one new list of 40 words on each of four successive days, each list being presented once only. Lists were presented by projecting words onto a curved perspex screen $25 \times 80 \mathrm{~cm}$ set at a distance of $60 \mathrm{~cm}$ from S. Presentation was self-paced, $S$ pressing a button to release one slide and present the next. Automatic timing apparatus recorded the duration of each presentation.

At the beginning of all sessions except the first, $S$ made a serial recall of the previous day's list, his spoken recall being recorded by $\mathrm{E}$. At the conclusion of the presentation of each of the four lists $S$ made an immediate recall in the same manner. Errors of recall were corrected. At the final session one day after the last presentation session $S$ made a spoken serial recall of the last list and was then asked to fill out a prepared form in any convenient order so as to reproduce all four lists in serial order.

Five lists each of 40 words were constructed, nouns chosen at random from the Thorndike-Lorge list of words occurring at least one per million words. Highly abstract nouns and nouns

Table 1 Recall Scores and Average Presentation Time

\begin{tabular}{cccccc}
\hline & \multicolumn{2}{c}{ Average Serial Recall Scores } & & $\begin{array}{c}\text { Free } \\
\text { Recall }\end{array}$ & $\begin{array}{c}\text { Presentation } \\
\text { Time }\end{array}$ \\
\cline { 2 - 3 } & $\begin{array}{c}\text { Immediate } \\
\text { Recall }\end{array}$ & $\begin{array}{c}\text { IDay } \\
\text { Delay }\end{array}$ & $\begin{array}{c}\text { Final } \\
\text { Session } \\
\text { (Variable } \\
\text { Delay) }\end{array}$ & $\begin{array}{c}\text { Final } \\
\text { Session } \\
\text { (Variable } \\
\text { Delay) }\end{array}$ & $\begin{array}{c}\text { Average time } \\
\text { per item } \\
\text { (sec) }\end{array}$ \\
\hline 1 & 38.2 & 38.4 & 19.8 & 31.4 & 13.24 \\
2 & 37.6 & 31.4 & 24.8 & 34.4 & 13.03 \\
3 & 35.8 & 30.2 & 31.8 & 36.6 & 14.33 \\
4 & 38.4 & 35.2 & 39.2 & 39.8 & 16.55 \\
\hline
\end{tabular}




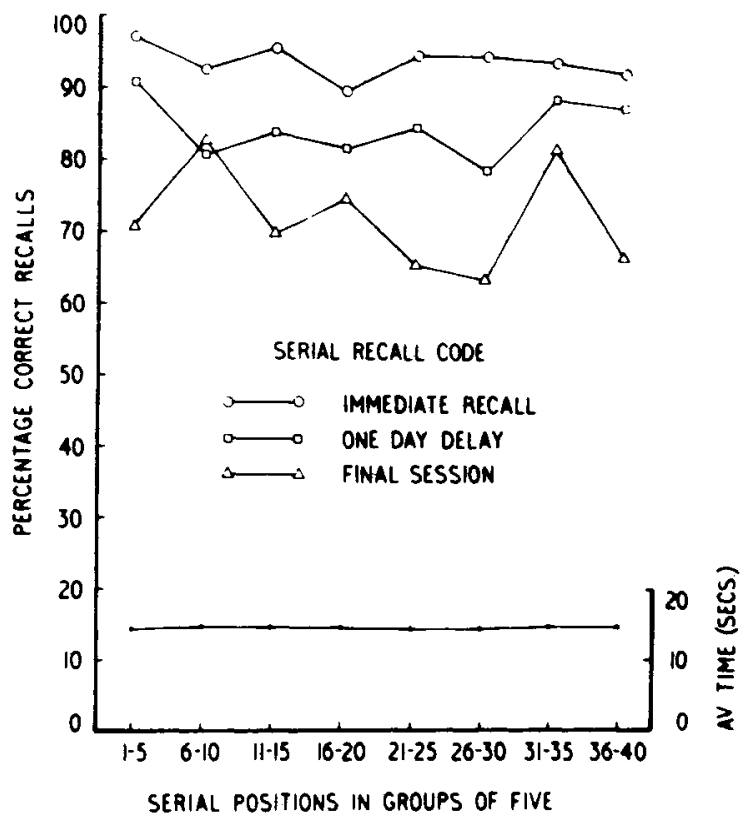

Fig. 1. Serial Position curves for recall at three delays (immediate, one day, and on the final session), and average presentation time.

susceptible to highly personal interpretation were rejected. Order of presentation was counterbalanced across Ss.

Results

Table 1 shows three average serial scores for the list presented in each of the four sessions, one for immediate recall, one for recall after one day, and one for recall at the final session. Table 1 also shows free recall scores (average number of items correct per list regardless of position) for the final session and the average presentation time per item for each list.

Figure 1 shows three serial position curves averaged over all Ss and all lists, one for immediate recall. one for recall after two days and one for recall at the final session. Items are grouped in sequences of five.

\section{DISCUSSION}

In Study $1 \mathrm{~S}$ recalled lists of 20 items or more with no errors or very few errors, and pairs of items with similar efficiency even after intervening tasks and no further presentations. Memory span is well beyond normal limits, and the capability for paired associate learning is even further beyond normal. More strikingly, interference effects are virtually eliminated. The single list of 50 concrete nouns in the first session was recalled in its original order with only two errors after a second presentation in a different order. Considerable retroactive inhibition effects are to be expected whether the task is regarded as serial learning or as paired associate learning, with the loci as stimuli and the list items as responses.

Repeated use of the same set of loci for new stimulus material did not produce detectable proactive or retroactive inhibition effects. Pairs of abstract nouns were mastered readily in the session following mastering of concrete nouns, and the concrete noun pairs were readily recalled, without error, at the end of the session. Both concrete and abstract noun pairs were recalled readily and without error in a later session after the loci had been used for groups of four words.

Study 2 confirmed that the system lifts serial learning performance well above normal limits and that interference effects seem to be confined to confusions between lists of items in corresponding serial positions, and affect performance to any marked clegree only with delayed serial recall in the final session.

Study 2 also shows that the normal serial position effect is undetectable even in delayed recall, a fact which gives substance to the impression, common to all Ss, that the whole list seems to be available simultaneously. Presentation time per item is also relatively uniform over list positions. (See Fig. 1.)

Blum, Graef, \& Hauenstein (1968) report exceptional memory both in waking and hypnotic states for a $\mathbf{S}$ trained to progress through a sequence of hypnotic trance stiges. Informal work with the memory-walk system shows comparable performance using the same consonant trigrams as Blum et al.

The performance found suggests a comparison with cases of exceptional memory. Luria (1960) reports a series of observations with Shereskevskii. He found "that there were practically no limits to his memory and that none of the methods at our disposal could reveal any limitations of his mnestic capabilities" (p. 82).

A consideration of Luria's report, of other studies of memory systems which provide exceptional recall, and of other relevant sources reveals several features in common wherever exceptional ability for serial recall is found. Firstly there always seems to be some equivalent both of Cicero's loci to provide distinctive "pegs," and of a serial ordering device, like the imaginary walk employed by the $S$ in this study.

Shereshevskii normally used places on a walk down Gorky Street from Pushkin Square. The Furst System (Furst, 1963) uses numbers to provide order and words derived from numbers by rules of numberphoneme equivalence to provide "pegs." Secondly, the method employed by $S$ is to imagine an event or scene which connects the items to be remembered with the locus or peg. Normally the method is to forge as striking (or bizarre or unusual) an image as can be invented. Thirdly, there is little or no attempt at rehearsal. Fourthly, it is common to use symbols or substitutes for words, particularly abstract words. One S used "celery" for "salary" in one instance, remembering when the time came to make the appropriate back substitution. The following example for legal counsel is given by the unknown author of Ad Herrenium: "We shall imagine the man in question as lying ill in bed, if we know him personally. If we do not know him, we shall yet take someone to be our invalid, but not a man of the lowest class, so that he may come to mind at once. And we shall place the defendant at the bedside, holding in his right hand a cup, in his left, tablets, and on the fourth finger, a ram's testicles. In this way we can have in memory the man who was poisoned, the witnesses, and the inheritance" (Yates, 1966, p. 11).

The elaboration of the invention and the use of symbolism impose a secondary load on memory since not only must the invention be recalled at the right time, but so also must the rules to decode it. Recall seems to be helped rather than hindered by elaboration despite the extra duty it entails. Whatever advantage it confers more than makes up for the extra burden on memory. As Cicero says, it is not true that "memory is crushed beneath a weight of images."

\section{REFERFNCES}

BLUM, G. A., GRAEF. J. R., \& HAUENSTEIN, L. S. Overcoming interference in short term memory through distinctive mental context. Psychonomic Science, 1968, 11, 73-74.

FURST, B. You can remember. Chicago Ill.: Memory and Concentration Studies, 1963.

LURIA, A. R. Memory and the structure of mental processes. Problems of Psychology, 1960, 4, 81-94.

YATES, F. A. The art of memory. London: Routledge and Kegan Paul, 1966. 